\title{
Assessment Of Peri-Implant Tissue Remodeling After Immediate Placement Of Implants Following Extraction In Maxillary Anterior Teeth: A One Year Prospective Pilot Study
}

Ranjani Thillaigovindan ${ }^{1 *}$, Shyam singh $^{2}$, Ranukumari $^{3}$, Shakila $^{3}$, Eswaran $^{4}$

${ }^{1}$ Reader, Department of prosthodontics, Thai Moogambigai Dental College and Hospital, Chennai, India.

${ }^{2}$ Director of PG studies, Department of prosthodontics, Maharana pratap dental college and Hospital, Gwalior, MP.

${ }^{3}$ Professor, Department of prosthodontics, Mahatma Gandhi PG institute of dental sciences, Puducherry.

${ }^{4}$ Professor, Department of prosthodontics, Thai Moogambigai Dental College and Hospital, Chennai, India.

\section{Abstract}

Background: Socket preservation following extraction of unrestorable tooth and restoring its form, function, and esthetics are the challenges faced by the implantologist and also the expectation of patients. Although earlier it was considered that long term implant survival depended on placement on healed alveolar ridge, current evidence confirms that immediate implant placement yields excellent and predictable results if established clinical guidelines are meticulously followed.

Aims: To assess the peri - implant hard and soft tissue remodeling around the immediately placed and immediately provisionalized dental implants in the maxillary anterior region.

Materials and Methods: In this pilot study, immediate implant placement and provisionalisation into the extracted sockets of maxillary anterior region was done in six patients. Clinical parameters were assessed after implant placement at 3, 6 and 12 months and compared with the values taken before extraction. Statistical analysis was done by repeated measures one-way ANOVA.

Results: The results revealed that, in comparison to the pretreatment values, there was a decrease in the height of papilla, width and thickness of mucosa. But there was no significant change in the mesial and distal marginal bone level and the success rate of implants is $100 \%$ which is comparable to any other study related to this subject.

Conclusion: The results obtained in this study reinforce the belief that the immediate implant loading is a good, reliable method especially in the esthetic zone with non-functional loading protocols. It could be extended for immediately loaded treatment solutions in the management of partially edentulous arches.

Keywords: Dental Implant; Immediate Provisionalisation; Peri-Implant Tissue; Attached Gingiva.

\section{Introduction}

Immediate placement of implants in an extraction socket has become a popular method in esthetic implant dentistry. The reason for the acceptance of this technique are related to an improved preservation of the soft tissue drape and the bone architecture compared with their collapse after tooth extraction. Further, it reduces the number of surgeries and decreases the treatment time [1-3]. The clinical success of immediate implants involves strict adherence to surgical techniques and certain prosthodontic considerations [4]. Achieving the primary stability through proper surgical technique is critical for the deposition of new bone around the implant. Prosthodontic considerations such as protection of the achieved primary stability and establishment of normal emergence profile results in optimal esthetic outcome $[5,6]$.

The effect of implant design, diameter and surface characteristics also influence the outcome of implant restoration in the anterior

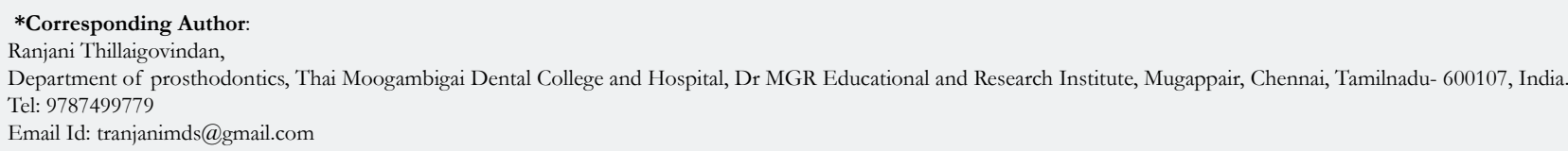

Citation: Ranjani Thillaigovindan, Shyam singh, Ranukumari, Shakila, Eswaran. Assessment Of Peri-Implant Tissue Remodeling After Immediate Placement Of Implants Following Extraction In Maxillary Anterior Teeth: A One Year Prospective Pilot Study. Int J Dentistry Oral Sci. 2021;08(03):2014-2019. doi: http://dx.doi.org/10.19070/2377-8075-21000396

Copyright: Ranjani Thillaigovindan ${ }^{\circ} 2021$. This is an open-access article distributed under the terms of the Creative Commons Attribution License, which permits unrestricted use, distribution and reproduction in any medium, provided the original author and source are credited. 
maxilla $[7,8]$. Studies have emphasized the importance of load free healing period in immediately placed implants for implant integration $[9,10]$.

Whenever an immediate extraction and implant insertion is contemplated, the soft tissue and bone comprise the major factors for single tooth peri-implant esthetics. This illustrates the need for evaluating the form of the periodontium before considering immediate implants and the need for periodic re-evaluation over a period of time. In this study the established keys for success of immediate implant survival namely proper case selection, atraumatic extraction with intact labial bone, implant selection, primary stability, and proper surgical technique and implant protected occlusion are reiterated for high survival rate of immediate loaded implants. Hence the aim of this study is to evaluate the peri-implant hard and soft tissues around the immediately loaded implants over a period of twelve months.

\section{Material and methods}

A total of six male patients whose maxillary anterior teeth were not restorable and willing for immediate implants were selected. The age of the patients ranged from 19 years to 45 years and in good health. These patients were treated with immediate dental implants (Nobel Bio-care) and provisional restoration cemented. The tooth involved did not have any evidence of clinical or radiographic pathological changes.

The selection criteria consisted of maxillary anterior teeth with vertical fracture, avulsed teeth, teeth with endodontic failure with no signs of infection, adequate bone quantity and quality (D2Misch bone density classification). Failing teeth with bone defect and evidence of infection was excluded from the study.

All the patients under went extraction of the central incisors done by an oral and maxillofacial surgeon followed by immediate implant placement by an experienced implantologist. The patients have given consent for their images and other clinical information to be reported in the journal and ethical committee clearance is obtained.

Clinical examination of the hard and soft tissues were routinely done before extraction of the teeth which formed the base line value of the study with which the post treatment values were compared. The hard tissue parameters consisted of evaluating the mesial and distal crestal bone height to the Cementoenamel junction using the calibrated tools in the Digital Radiovisuography (Schick 33, Sirona).

The soft tissue parameters consisted of evaluating the soft tissue margin level which is the distance between the most apical point of the soft tissue margin at the facial aspect of the crown and a line connecting the mid facial level of soft tissue margin at the adjacent teeth, mesial and distal papilla height, width of the keratinized mucosa, probing depth and thickness of the mucosa (Figures 1, 2, 3 and 4). These were measured to the nearest $0.5 \mathrm{~mm}$ with Williams's periodontal probe. The values obtained were set as baseline value. The teeth to be replaced with immedi-

Figure 1. Measuring the width of the keratinized mucosa.

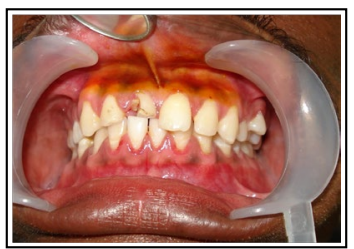

Figure 2. Soft tissue margin level.

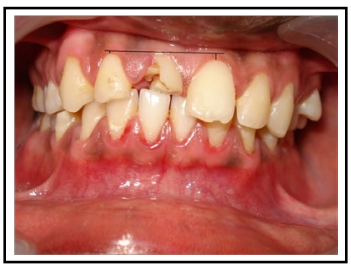

Figure 3. Papilla height.

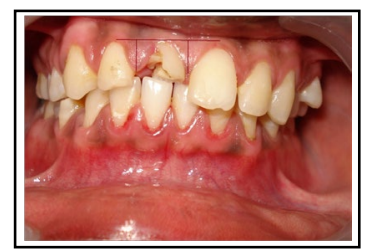

Figure 4. Measuring the thickness of attached gingiva.

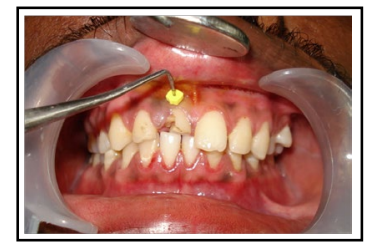


ate implants were extracted with minimal trauma using periotome. After the extraction the integrity of the labial plate was verified using a periodontal probe. This was followed by immediate implant placement and provisional restoration. Primary implant stability is a prerequisite for immediate implant placement and provisional restoration which was achieved by engaging the palatal wall and placing the implant $4-5 \mathrm{~mm}$ beyond the apex of the extraction socket. The clinical parameters were again measured at third month, sixth month and twelfth month following implant placement and compared with the baseline [11].

All the patients treated with immediate implants underwent the same preoperative investigations. Preoperative radiographs were taken and the magnification factor for each of the radiograph was calculated with a marker of known dimension $(3.8 \mathrm{~mm})$. Actual root length was calculated using the formula: Actual root length = radiographic root length/ radiographic diameter of marker $\times$ actual diameter of the marker. The quantity of bone was assessed by measuring the amount of bone present between the floor of the nasal cavity and the apex of the tooth as it is the prerequisite for achieving primary stability [12]. Most of the fresh extracted socket in maxillary anterior region are categorized as type II, i.e. D2 (Misch bone density classification). So, the success rate of immediate implant placement in this area is expected to be high.

Diagnostic impressions of the dental arches were made with an irreversible hydrocolloid impression material and diagnostic casts obtained [13]. Patients selected for the implant therapy were premedicated with suitable antibiotics, anti-anxiety drug from the previous night of proposed surgery. Patient was also advised to use $0.12 \%$ chlorhexidine mouth wash $2-3$ times for 3 days prior to surgery. Atraumatic extraction of the tooth to be replaced was performed without disturbing the socket walls. After extraction of the tooth, the width of the root was measured at $2 \mathrm{~mm}$ below the cemento-enamel junction using Iwanson metal caliper and length of the root was measured using a metal ruler.

Osteotomy was done through the socket opening with twist drill (Figure 5). The longest and widest possible implants were selected to be placed in the immediate extraction socket. The implant was unpacked from its gamma sterilized pack and placed into the prepared socket with the wrench. Non resorbable silk sutures were placed interdentally to aid in soft tissue approximation. Radiographs were taken post operatively to confirm its position. Either a straight or angulated abutment was selected depending on the angulation of the implant placed and restored immediately with custom made provisional restoration using tooth colored acrylic resin by indirect technique. Implant protected occlusion is given to aid in osseointegration.

Patients were evaluated clinically and radiographically at implant placement and at 3, 6, and 12 months after implant placement [14]. Clinical parameters were measured using Peridontometerinset with titanium tip used specifically around titanium coated implants during the follow-up. Permanent metal- ceramic restoration was given after three months and the follow up was continued as per the patient's convenience only as routine dental checkup (Figure 6).

\section{Results}

The clinical parameters were assessed for all the six patients before extraction and after implant placement at third, sixth and twelfth month. The values were recorded and compared using repeated measures ANOVA (Tables 1 and 2).

\section{The Following Interpretations Were Drawn:}

It was observed that in all the cases there was significant differences in the plaque index scores $(\mathrm{f}=4.24, \mathrm{p}=0.03)$. From pretreatment- 3 months $(\mathrm{MD}=0.80 \pm 0.20 \mathrm{SE}, \mathrm{P}<0.05)$ the change is positive which indicates that the plaque control measures taken by the patients were not effective. From 3 months - 6 months $(\mathrm{MD}=-0.60 \pm 0.24 \mathrm{SE}, \mathrm{P}<0.05)$ the change is negative which indicates that effective plaque control measures were taken by the patient when compared to the first time interval.

The mid facial level of marginal gingiva shows statistically significant difference $(\mathrm{f}=3.13, \mathrm{p}>0.05)$ from 3 months -6 months $(\mathrm{MD}=-0.70 \pm 0.12 \mathrm{SE}, \mathrm{P}<0.02)$. This indicates that the change in the mid facial level of marginal gingiva is affected mostly during the second time interval.

The height of mesial papilla from pretreatment to different time periods $(\mathrm{f}=12.71, \mathrm{p}<0.01)$ shows significant difference. From pretreatment to 3 months $(\mathrm{MD}=1.00 \pm 0.22 \mathrm{SE}, \mathrm{P}=0.00)$, from pretreatment to 6 months $(\mathrm{MD}=1.30 \pm 0.20 \mathrm{SE}, \mathrm{P}=0.00)$, and from pretreatment to 12 months $(\mathrm{MD}=1.30 \pm 0.20 \mathrm{SE}, \mathrm{P}=$

Figure 5. Preparation of the osteotomy site.

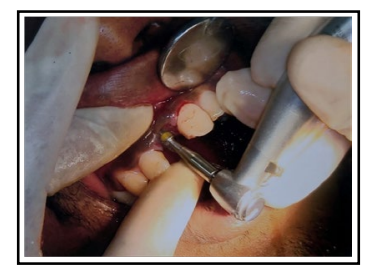

Figure 6. Single-tooth metal ceramic restoration.

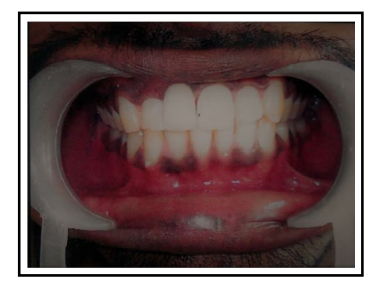


Table 1. Marginal bone level assessment at pretreatment and post implant treatment intervals.

\begin{tabular}{|c|c|c|c|c|c|}
\hline Parameters & $\begin{array}{c}\text { Pretreat- } \\
\text { ment3months } \\
\text { Mean } \pm \text { SD }\end{array}$ & $\begin{array}{c}\text { 3-6 months } \\
\text { Mean } \pm \text { SD }\end{array}$ & $\begin{array}{c}\text { 6-12 months } \\
\text { Mean } \pm \text { SD }\end{array}$ & $\begin{array}{c}\text { Pretreatment- } \\
\text { 6months } \\
\text { Mean } \pm \text { SD }\end{array}$ & $\begin{array}{c}\text { Pretreatment } \\
\text { 12 months } \\
\text { mean } \pm \text { SD }\end{array}$ \\
\hline $\begin{array}{c}\text { Mesial marginal } \\
\text { bone level }\end{array}$ & $-0.18 \pm 0.34$ & $0.17 \pm 0.14$ & $-0.24 \pm 0.28$ & $-0.01 \pm 0.41$ & $-0.25 \pm 0.63$ \\
\hline $\begin{array}{c}\text { Distal marginal } \\
\text { bone level }\end{array}$ & $-0.14 \pm 0.29$ & $0.51 \pm 0.59$ & $-0.07 \pm 0.09$ & $0.38 \pm 0.54$ & $0.31 \pm 0.59$ \\
\hline
\end{tabular}

( $\mathrm{p}$ value included in the text)

Table 2. Soft tissue assessment at Pretreatment and Post implant treatment intervals.

\begin{tabular}{|c|c|c|c|c|c|}
\hline Parameters & $\begin{array}{c}\text { Pretreatment } \\
\text { Mean } \pm \text { SD }\end{array}$ & $\begin{array}{c}\text { 3-6months } \\
\text { Mean } \pm \text { SD }\end{array}$ & $\begin{array}{c}\mathbf{6} \text {-12months } \\
\text { Mean } \pm \text { SD }\end{array}$ & $\begin{array}{c}\text { Pretreatment } \\
\text { - 6months } \\
\text { Mean } \pm \text { SD }\end{array}$ & $\begin{array}{c}\text { Pretreatment } \\
\text { 12 } \text { months } \\
\text { Mean } \pm \text { SD }\end{array}$ \\
\hline Modified Plaque Index & $0.80 \pm 0.20$ & $-0.60 \pm 0.24$ & $0.00 \pm 0.32$ & $0.20 \pm 0.20$ & $0.20 \pm 0.20$ \\
\hline $\begin{array}{c}\text { Changes in the level of } \\
\text { Marginal Gingiva }\end{array}$ & $0.60 \pm 0.37$ & $-0.70 \pm 0.12$ & $0.00 \pm 0.00$ & $-0.10 \pm 0.37$ & $-0.10 \pm 0.37$ \\
\hline Papilla Height (M) & $1.00 \pm 0.22$ & $-0.3 \pm 0.20$ & $0.00 \pm 0.00$ & $1.30 \pm 0.20$ & $1.30 \pm 0.20$ \\
\hline Papilla Height (D) & $0.70 \pm 0.12$ & $0.50 \pm 0.22$ & $0.10 \pm 0.10$ & $1.20 \pm 0.12$ & $1.30 \pm 0.12$ \\
\hline Width of attached Mucosa & $0.64 \pm 0.10$ & $0.70 \pm 0.12$ & $0.00 \pm 0.00$ & $1.34 \pm 0.10$ & $1.34 \pm 0.10$ \\
\hline $\begin{array}{c}\text { Probing Depth (Mesio- } \\
\text { Buccal) }\end{array}$ & $-0.20 \pm 0.37$ & $-0.40 \pm 0.19$ & $0.00 \pm 0.00$ & $-0.60 \pm 0.37$ & $-0.60 \pm 0.37$ \\
\hline Mesio-Lingual & $0.10 \pm 0.46$ & $-0.60 \pm 0.19$ & $-0.50 \pm 0.22$ & $-0.50 \pm 0.50$ & $-1.00 \pm 0.42$ \\
\hline Disto-Buccal & $-0.30 \pm 0.25$ & $-0.20 \pm 0.12$ & $-0.20 \pm 0.12$ & $-0.50 \pm 0.16$ & $-0.70 \pm 0.12$ \\
\hline Disto-Lingual & $0.00 \pm 0.27$ & $-0.60 \pm 0.33$ & $-0.40 \pm 0.19$ & $-0.60 \pm 0.19$ & $-1.00 \pm 0.22$ \\
\hline Facial & $-0.20 \pm 0.25$ & $0.20 \pm 0.20$ & $0.10 \pm 0.10$ & $0.00 \pm 0.16$ & $0.10 \pm 0.19$ \\
\hline Lingual & $-0.20 \pm 0.25$ & $0.20 \pm 0.25$ & $0.10 \pm 0.29$ & $0.00 \pm 0.22$ & $0.10 \pm 0.33$ \\
\hline Thickness of Mucosa & $1.8 \pm 0$ & $1.55 \pm 0.11$ & $1.5 \pm 0$ & $1.5 \pm 0$ & 23.416 \\
\hline
\end{tabular}

0.00) the changes are significant. This indicates that the height of mesial papilla has decreased during these time periods.

Also the distal papilla height $(\mathrm{f}=30.29, \mathrm{p}=0.00)$ from pretreatment to different time periods, shows that it is affected by time. From pretreatment -3 months $(\mathrm{MD}=0.70 \pm 0.12 \mathrm{SE}, \mathrm{P}=0.00$ ), from pretreatment -6 months $(\mathrm{MD}=1.20 \pm 0.12 \mathrm{SE}, \mathrm{P}=0.00)$, and from pretreatment -12 months $(\mathrm{MD}=1.30 \pm 0.12 \mathrm{SE}, \mathrm{P}$ $=0.00)$ the changes are significant, indicating that the height of distal papilla decreased during these time periods.

The width of attached gingiva has also decreased with time ( $\mathrm{f}=$ $30.29, \mathrm{p}=0.00)$. From pretreatment -3 months $(\mathrm{MD}=0.64 \pm$ $0.10 S E, P=0.00)$, from pretreatment -6 months $(\mathrm{MD}=1.34 \pm$ $0.10 \mathrm{SE}, \mathrm{P}=0.00)$, and from pretreatment -12 months $(\mathrm{MD}=$ $1.34 \pm 0.10 \mathrm{SE}, \mathrm{P}=0.00$ ) the changes are significant.

There is no significant change in the probing depth in mesio-buc$\mathrm{cal}$, facial and lingual regions from pretreatment to different time periods (3, 6, and 12 months). Increase in probing depth is found in mesio-lingual region during the period from pretreatment to 12 months $(\mathrm{MD}=-1.00 \pm 0.42 \mathrm{SE}, \mathrm{P}=0.02)$. The probing depth around distobuccal $(\mathrm{MD}=-0.50 \pm 0.16 \mathrm{SE}, \mathrm{P}=0.03)$, and distolingual $(\mathrm{MD}=-0.60 \pm 0.19 \mathrm{SE}, \mathrm{P}=0.03)$ regions were found to be significantly increased especially during pretreatment to 6 month time period.

No statistically significant difference were found in the mesial and distal marginal bone level from pretreatment to different time periods (3, 6 and 12 months) [15-18].

\section{Discussion}

With immediate implant placement the total time period is reduced, which is usually appreciated by the patients. In addition, bone resorption is reduced and the implant can be placed in an identical position and with the same inclination as the natural tooth it replaced [15]. In the present study the patients underwent extraction of central incisors with unrestorable crowns followed by immediate implant placement and provisionalisation (With in 24 hours), there by reducing the treatment time.

In the present study the mean marginal bone level, initially decreased from the stage of implant placement to three months. Later, there was bone gain around the implants for twelve subjects, where as there was no significant bone gain for the remaining eight implants. Similar studies done by Eivind Andersen, Hans Reidar Haanes and Bjorn Mork Knutsen showed that the change in mean marginal bone level was very favorable, with $88 \%$ of the implants showing bone gain at the end of the investigation peri- 
od. Kitichai Rungcharassaeng showed that there was a significant marginal bone change during the first six months after loading, after which there was no significant change [16-18].

In the present study there was a significant recession in the mid facial level of the marginal gingival during the first six months. Thus resulting in a significant decrease in the width of the attached gingiva [19-22]. This was similar to that observed by Chang M, Wennstrom, Odman P and Andersson who stated that the soft tissue margin at both facial and proximal implant sites was more apically located than the gingival margin at corresponding sites at the contralateral tooth [4].

In the present study there was an unfavorable decrease in the papilla height around provisional restoration which was significant till 3 months, later the papilla height was maintained. The height of the mesial and distal papilla has significantly decreased compared to the pretreatment period. Studies by Eivind Andersen et al showed that temporary crown had a positive impact on the soft tissue with respect to the preservation of the papillae. The mucosal health adjacent to the implants were initially unsatisfactory but this improved after three months $[21,17]$.

Implants placed in the extracted socket exhibited superior results than those in the healed site due to the increased metabolic activity of bone in the extracted socket as emphasized by Young Hwan Jo, Peter K. Hobo and Sumiya Hobo. They also found that the results in the maxilla were more favorable than those in the mandible $[23,24]$.

The cases involved in the present study underwent an atraumatic extraction. The implants used in this study were of the size of $5 \mathrm{~mm}$ diameter and $16 \mathrm{~mm}$ length for six patients and $14 \mathrm{~mm}$ length for the remaining fourteen patients. They were placed $1-2 \mathrm{~mm}$ below the crest of the alveolar bone to achieve proper emergence profile for the restoration and engaged $3-5 \mathrm{~mm}$ of apical bone for primary stability. This is in accordance with the studies by Richard J. Lazzara, who showed that the coronal aspect of the implant should be placed atleast $2 \mathrm{~mm}$ apical to the surrounding osseous crest. Bo Rosenquist and Bjorn Grenthe placed all implants by atleast $5 \mathrm{~mm}$ beyond their apical portion for gaining initial stability $[3,25]$.

The modified plaque index scores in the study indicated that there was improvement in plaque control measures taken by the patient across the time period which helped in maintaining the probing depth. A study by Kitichai Rungcharassaeng evaluated the periimplant parameters and found that the mean modified plaque index had significantly decrease with time. There was a significant decrease in mean probing depth from 1 to 3 months, but it remained stable thereafter [26].

In this study all the implants placed were successfully osseointegrated accounting for $100 \%$ success rate. Various authors have mentioned the success rate of immediate implants. Dale E. Smith and George A. Zarb have proposed various criteria for the success of osseointegrated implants [27]. Joseph Y.K.Kan and Kitichai Rungcharassaeng in 2003 reported a cumulative success rate of $100 \%$ in a one year prospective study conducted on immediately placed and provisionalized maxillary anterior implants [14]. Dean Morton and Robert Jaffin in 2004 reported a cumulative success rate of $98.6 \%$ and $99.1 \%$ in a study conducted on im- mediate functional loading and nonfunctional loading implants respectively [28].

\section{Conclusion}

Through proper patient selection and controlled surgical techniques we were able to achieve favorable implant success rates and periimplant tissue response with immediate provisional restoration of implants in the esthetic zone in this pilot study [29, 30]. But bone was not regularly maintained at the original levels around the implants. But still with this pilot study we were able to evaluate the feasibility of resources and other problems associated with the follow up of the study. We hope a large scale study could be feasible with implants of reasonable cost in conjunction with guided bone regeneration procedures. Also with the development of autogenous tooth bone graft material made by extracted tooth chair side, immediate implant placement in fresh socket with facial bone defect also could be considered [31-33]. This may further expand the selection criteria with appropriate use of regenerative procedures.

\section{References}

[1]. Schwartz- Arad D, Chaushu G. The ways and wherefores of immediate placement of implants into fresh extraction sites: A literature review. J Periodontol 1997; 68:915-923.

[2]. Wagenberg B, Froum SJ. A Retrospective study of 1,925 consecutively placed immediate implants from 1988 to 2004. Int J Oral Maxillofac Implants 2006; 21: 71-80.

[3]. Lazzara RJ. Immediate placement of implants into extraction sites. Oral and Maxillofac Surgery Clin of North Am 1991; 3:921-934.

[4]. Chang M, Wennstrom JL, Odman P, Andersson B. Implant supported single - tooth replacements compared to Contralateral natural teeth. Clin Oral Impl Res 1999; 10: 185-194.

[5]. Proussaefs P, Kan J, Lozada J. Effects of immediate loading with threaded hydroxyapatite-coated root-form implants on single premolar replacements: A preliminary report. Int J Oral Maxillofac Implants 2002; 17:567-572.

[6]. Belser UC, Schmid B, Higginbottom F et al. Outcome analysis of implant restorations located in anterior maxilla: A Review of recent literature. Int J Oral Maxillofac Implants 2004; 19: 30-42.

[7]. Hall JA, Payne AG, Purton DG et al. Immediately restored, single- tapered implants in the anterior maxilla: Prosthodontic and esthetic outcomes after one year. Clin Implant Dent Relat Res 2007; 9:34-45.

[8]. Calvo Guirado JL, Saez Yuguero MR, Pardo Zamorag, Munoz Barrio E. Immediate provisionalisation on a new implant design for esthetic restoration and preserving crestal bone. Implant Dent 2007; 16:155-64.

[9]. Kim Y,Oh T-J, Misch CE, Wang H-L. Occlusal considerations in implant therapy: clinical guidelines with biomechanical rationale. Clin Oral Impl Res 2005; 16: 26-35.

[10]. Lorenzoni M, Pertl C, Zhang K, Wimmer G, Wegscheider WA. Immediate loading of single- tooth implants in the anterior maxilla. Preliminary results after one year. Clin Oral Impl Res 2003; 14: 180-187.

[11]. Salvi GE, Lang N. Diagnostic parameters for monitoring peri-implant conditions. Int J Oral Maxillofac Implants 2004; 19(suppl): 116-127.

[12]. Goodacre CJ, Bernal G, Rungcharassaeng K et al. Clinical complications with implants and implant prostheses. J Prosthet Dent 2003; 90: 121-132.

[13]. Leary JC, Hirayama M. Extraction, immediate -load implants, impressions and final restorations in two patient visits. JADA 2003; 134: 715-720.

[14]. Kan JYK, Rungcharassarng K. Immediate placement and provisionalization of maxillary anterior single implants: 1- year prospective study. Int J Oral Maxillofac Implants 2003; 18: 31-39.

[15]. Gapski R, Wang HL, Mascarenhas P, Lang NP. Critical review of immediate implant loading. Clin Oral Impl Res 2003; 14: 515-527.

[16]. Lang NP, Pun L, Lau KY, Li KY, Wong MC. A Systematic review on survival and success rates of implants placed immediately into fresh extraction sockets after atleast 1 year. Clinical oral implants research 2012; 23 (suppl):39-66.

[17]. Andersen E, Haanaes HR, Knutsen BM. Immediate loading of single tooth ITI implants in the anterior maxilla: a prospective 5- year pilot study. Clin Oral Impl Res 2002; 13: 281-287.

[18]. Hartman GA, Cochran DL. Initial implant position determines the magnitude of crestal bone remodeling. J Periodontol 2004; 75: 572-577. 
[19]. De Rovck T, Collys K, Cosyn J. Immediate single tooth implants in the anterior maxilla: A 1-year case cohort study on hard and soft tissue response. J clin Periodontol 2008; 35:649-657.

[20]. Ross SB, Pette GA, Parker WB,Hardigan P. Gingival margin changes in maxillary anterior sites after single immediate implant placement and provisionalization: a 5-year retrospective study of 47 patients. Int $j$ oral maxillofac implants 2014; 29(1):127-34.

[21]. De Rouck T, Collys K, Cosyn J. Single -tooth replacement in the anterior maxilla by means of immediate implantation and provisionalization: a review. The international journal of oral and maxillofacial implants 2008; 23(5):897-904.

[22]. Chen ST, Buser D: Esthetic outcomes following immediate and early implant placement in the anterior maxilla - a systematic review. The international journal of oral and maxillofacial implants 2014; 29:186-215.

[23]. Ganeles J, Wismeijer D. Early and immediately restored and loaded dental implants for single-tooth and partial-arch applications. Int J Oral Maxillofac Implants 2004; 19(suppl): 92-102.

[24]. Jo HY, Hobo PK, Hobo S. Freestanding and multiunit immediate loading of the expandable implant: An up-to-40 month prospective survival study. J Prosthet dent 2001; 85(2):148-155.

[25]. Rosenquist B, Grenthe B. Immediate placement of implants into extraction sockets: Implant survival. Int J Oral Maxillofac Implants 1996; 11:205-209.

[26]. Rung charassaeng K. Peri-implant tissue response of immediately loaded, threaded, HA- coated implants: 1-year results. J Prosthet Dent 2002; 87:
173-181.

[27]. Smith DE and Zarb GA. Criteria for success of osseointegrated endosseous implants. J Prosthet Dent 1989; 62:567-72.

[28]. Morton D, Jaffin R, Weber HP. Immediate restoration and loading of dental implants: Clinical considerations and protocols. Int J Oral Maxillofac Implants 2004; 19: 103-108.

[29]. Hartlev J, Kohberg P, Ahlmann S et al. Immediate placement and provisionalization of single -tooth implants involving a definitive individual abutment: a clinical and radiographic retrospective study. Clin oral implant res 2013; 24(6):652-8.

[30]. Cosyn J, Eghbali A, De Bruyn H et al. Immediate single -tooth implants in the anterior maxilla: 3-year results of a case series on hard and soft tissue response and aesthetics. J Clin Periodontol 2011; 38(8):746-53.

[31]. S Miguel, BC Filipa, JM Beatriz. Immediate loading of single implants in the anterior maxilla: A 1- Year prospective clinical study on 34 patients. International Journal of Dentistry 2017; Article ID 8346496: 1-11.

[32]. Kan JYK, Rungcharassaeng K, Deflorian M, Weinstein T, Wang HL, Testori T. Immediate implant placement and provisionalisation of maxillary anterior single implants. J Periodontology 2018:77:197-212.

[33]. Wu D, Zhou L, Lin J, Chen J, Huang W and Chen Y. Immediate implant placement in anterior teeth with grafting material of autogenous tooth bone Vs xenogenic bone. BMC oral health 2019:19:266. 